\title{
ABBREVIATIONS
}

$\begin{array}{ll}\text { KBHT } & \text { Kindai bungaku hyōron taikei } \\ \text { MBZ } & \text { Meiji bungaku zenshū } \\ \text { NBKSS } & \text { Nihon bungaku kenkyū shiryō sōsho } \\ \text { NKBT } & \text { Nihon koten bungaku taikei } \\ \text { NKiBT } & \text { Nihon kindai bungaku taikei } \\ \text { SNKBT } & \text { Shin Nihon koten bungaku taikei } \\ \text { SNKBTM } & \text { Shin Nihon koten bungaku taikei Meiji-hen } \\ \text { SNKBZ } & \text { Shinpen Nihon koten bungaku zenshū }\end{array}$





\section{LICENTIOUS FICTIONS}


